\title{
Erratum to "Is Aggressive Trait Responsible for Violence? Priming Effects of Aggressive Words and Violent Movies" [Psychology 4 (2013) 96-100]
}

\author{
Qian Zhang, Lixin Wang \\ School of Applied Technology, Southwest University, Chongqing, China \\ Email: zhq@swu.edu.cn
}

Received: November 15, 2012

Accepted: December 17, 2012

Published: January 10, 2013

Copyright (C) 2019 by author(s) and Scientific Research Publishing Inc. This work is licensed under the Creative Commons Attribution International License (CC BY 4.0).

http://creativecommons.org/licenses/by/4.0/

(c) $\underset{\mathrm{EY}}{\mathrm{G}}$ Open Access

The original online version of this article (Zhang, Q., Zhang, D. J., \& Wang, L. X. (2013) Is Aggressive Trait Responsible for Violence? Priming Effects of Aggressive Words and Violent Movies. Psychology, 4, 96-100. http://dx.doi.org/10.4236/psych.2013.42013) was published as some results data reported mistakenly. The author wishes to correct the errors to:

\begin{abstract}
The aim of the present study was to examine the priming effects of violent movies and aggressive words on implicit aggression by using modified STROOP task. 190 adolescents participated in this study, with 95 assigned to non-violent movie group and 95 assigned to violent movie group. The results showed that no significant difference was found in the main affect of Movie Type, but it revealed significant Movie Type $\times$ Aggressive Trait interaction, and that aggression was significantly influenced by violent movie only for high-aggressive trait (HT) adolescents, but not under condition of nonviolent movie. The possible underlying mechanism was that HT adolescents may possess a relatively stronger aggressive network of cognitive association which was easily activated by violent movie. This indicated that violent movie could effectively elicit implicit aggression for adolescents who were highly aggressive, but not for nonaggressive adolescents.
\end{abstract}

\section{Method}

The total participants were 190 adolescents (95 boys, 95 girls) from a small high school in the southwestern area of China. Adolescents ranged in age from 15 to 
19 years $(M=16.22, S D=1.60)$.

\section{Experimental Design}

Multi-factorial design was used, with Movie Type and Aggressive Trait as independent variables and Aggression as dependent variable. 2 (Movie Type: violent vs. non-violent) $\times 3$ (Aggressive Trait: HT, MT, LT) repeated two measures analysis of variance $(A N O V A)$ was conducted with Movie Type and Aggressive Trait as between-group factor, and Goal Word as within-group factor. According to score distribution, participants who got score at the top of $27 \%$ on Buss Perry Aggression Questionnaire (BPAQ) were defined as HT, and the last 27\% were seen as LT, and the rest were considered as MT.

\section{Results}

The Main Effect of Movie Type, Movie Type $\times$ Aggressive Trait Interaction

In the study, we would like to verify the aggressively priming effect of violent movie and aggressive word on implicit aggression, and postulated each participant had a mean aggressively priming score (APS), which meant the calculated score for the mean RT value of aggressive words minus nonaggressive words and divide by 2 for the violent movie group (THE BIG FAT KILL), and found whether significant difference of APS in group type (See Table 1).

MANCOVA in APS between movie type and aggressive trait.

\begin{tabular}{c|c|c|}
\hline Independent variables & \multicolumn{2}{c|}{ Mean Square F } \\
\hline Movie type & 6033.57 & 1.79 \\
\hline Movie type $\times$ Aggressive trait & $15,130.63$ & $4.09^{*}$ \\
\hline
\end{tabular}

Note: ${ }^{*} p<0.05$.
Multivariateanalysis of covariance (MANCOVA) was used to test whether
significant difference was found in APS among independent variables (See Table
1). Table 1 showed no significant difference in main effect of movie type on ag-
gression $(F(1,184)=1.79, p>0.05)$.
As can be seen in Table 1, there was a significant Movie Type $\times$ Aggressive
Trait interaction $(F(2,184)=4.09, p<0.05)$. Further simple effect analysis
showed that aggression of HT adolescents was significantly elicited by violent
movie clips $(F(2,184)=5.46, p<0.01)$. But no significant aggression difference
was elicited by nonviolent movies $(F(2,184)=2.79, p>0.05$; See Table 2$)$.
Table 2. Post Hoc in APS among aggressive traits by watching movie clips.

\begin{tabular}{ccccc|}
\hline Aggressive trait & $\begin{array}{c}\text { High-aggressive } \\
\mathrm{M}(\mathrm{SD})\end{array}$ & $\begin{array}{c}\text { Mid-aggressive } \\
\mathrm{M}(\mathrm{SD})\end{array}$ & \multicolumn{2}{c|}{$\begin{array}{c}\text { Low-aggressive F } \\
\mathrm{M}(\mathrm{SD})\end{array}$} \\
\hline Violent & $128.37(10.24)$ & $86.64(8.93)$ & $141.17(15.26)$ & $5.46^{* *}$ \\
\hline Non-violent & $128.97(16.80)$ & $102.47(8.83)$ & $84.69(9.82)$ & 2.79 \\
\hline \hline Note: ${ }^{* *} p<0.01$. & & & & \\
\hline
\end{tabular}

